\title{
Structure Properties of AlSi7Mg/SiC Composite Produced by Stir Casting Method
}

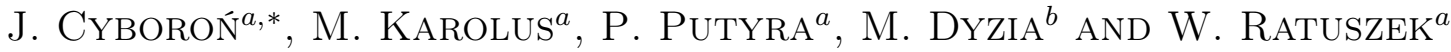 \\ ${ }^{a}$ The Institute of Advanced Manufacturing Technology, Wrocławska 37a, Krakow, Poland \\ ${ }^{b}$ Silesian University of Technology, Z. Krasińskiego 8, 40-019 Katowice, Poland
}

\begin{abstract}
The paper presents the structure studies on composites of aluminum alloy matrix with addition of silicon carbide phase (from 5 to 15 vol.\% $\mathrm{SiC}$ and 10 vol.\% $\mathrm{SiC}+10$ vol.\% graphite) obtained by the stir casting method. The aim of this work is to determine the influence of the $\mathrm{SiC}$ content and electrical discharge machining processes on the phase composition, microstructure, and values of residual stresses. In order to determine the heterogeneity of the obtained materials, the X-ray diffraction analysis was performed in different sample orientations to the direction of the X-ray beam (perpendicular and parallel), using different geometries (the Bragg-Brentano and grazing incident X-ray diffraction). This work presents the results of the residual stress analysis in the tested composites generated by various content of $\mathrm{SiC}$ additives. Residual stresses were determined by both of the $\sin ^{2} \psi$ and $g-\sin ^{2} \psi$ X-ray methods. Obtained results shown the significant gradient of residual stress in all cases.
\end{abstract}

DOI: 10.12693 /APhysPolA.130.969

PACS/topics: 81.65.Ps, 83.85.Hf, 81.05.Mh

\section{Introduction}

Aluminum alloys with ceramic additives composites are combinations of two different phases. Addition of $\mathrm{SiC}$ particles - characterized by good physical and mechanical properties such as high strength, hardness, resistance to high temperature, corrosion, and abrasion [1] — into metal matrix alloy improves their properties and makes it much more useful in different applications. However, large differences in physical and mechanical properties of aluminum and ceramic might create, in the place of their connection, residual stresses. The difference in thermal expansion coefficients between ceramics and metal have got the biggest impact on the level and distribution of this stresses. Furthermore, aluminum/ceramic composites require suitable machining to give the proper shape and dimensions. One type of surface machining is electrical discharge machining (EDM). The material removal in this process is associated with the impact of thermal electrical discharge which follows to a local increase in temperature (mostly in the range of 8,000 $\left.12,000^{\circ} \mathrm{C}[2,3]\right)$. These high temperatures change the metallographic structure and state of residual stress in the obtained surface layer [4]. Improper conditions are generated by tensile residual stress which causes creation of microcracks. The prediction of residual stresses involves a fine coupling of all these approaches.

The main purpose of this paper is to determine the influence of EDM process and different amounts of ceramic reinforcement (from 5 vol.\% to 15 vol.\%) on the phase composition, microstructure, residual stress in the composite material AlSi7Mg with silicon carbide addi-

\footnotetext{
* corresponding author; e-mail: jolanta. cyboron@ios. krakow.pl
}

tion. Additionally, the results obtained for material with 10 vol.\% $\mathrm{SiC}[5]$ are compared to the results obtained for material reinforced with $10 \mathrm{vol} . \% \mathrm{SiC}$ and $10 \mathrm{vol} . \%$ graphite.

\section{Research material}

Silumins matrix composite AlSi7Mg with different amount of silicon carbide addition are chosen as the tested material. In Table I there is shown the chemical composition of aluminum matrix.

TABLE I

Chemical composition of AlSi7Mg matrix [wt\%].

\begin{tabular}{c|c|c|c|c|c|c}
\hline \hline $\mathrm{Si}$ & $\mathrm{Fe}$ & $\mathrm{Cu}$ & $\mathrm{Mn}$ & $\mathrm{Mg}$ & $\mathrm{Zn}$ & $\mathrm{Al}$ \\
\hline $6.5-7.5$ & 0.6 & 0.2 & 0.4 & $0.2-0.7$ & 0.2 & bal.
\end{tabular}

Metal matrix composite with ceramic reinforcement were obtained by stir casting (suspension) method. Process was conducted in two stages. In first step, the silicon carbide particles, were preheated to temperature $350^{\circ} \mathrm{C}$ and next added to the liquid metal at $720^{\circ} \mathrm{C}$. In the second step, the suspension was placed in hermetic chamber which enabled proper degassing and homogenization under reduced pressure conditions [6]. After that the materials were cut using EDM process. In Table II there are shown the EDM parameters.

TABLE II

The EDM parameters. $T_{i}[\mu \mathrm{s}]$ - pulse time, $T_{0}[\mu \mathrm{s}] \quad$ interval time between pulses, $I[\mathrm{~A}]$ - amplitude of the current in pulse, $U_{z}[\mathrm{~V}]$ - voltage.

\begin{tabular}{c|c|c|c}
\hline \hline$T_{i}$ & $T_{0}$ & $I$ & $U_{z}$ \\
\hline 4 & 10 & 3 & 90
\end{tabular}




\section{Phase analyses}

The X-ray diffraction (XRD) measurements were performed by the PANalytical Empyrean diffractometer using copper radiation $\left(\lambda_{C u}=1.5406 \AA\right)$. The phase analyses were done using the ICDD PDF-4+ 2014 files. The quantitative phase analyses of studied materials were performed by the Rietveld refinement [7] by using the High Score Plus PANalytical software. In order to investigate the heterogeneity of tested materials, measurements were conducted in different orientation of the specimen short and long diagonal parallel to the primary beam direction (Fig. 1).

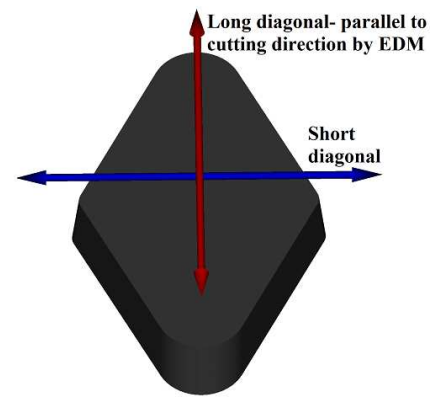

Fig. 1. Shape and orientations of samples regarding to direction of cutting and to primary X-ray beam.

The results of phase analysis of the studied samples after EDM process are presented in Table III.

TABLE III

Results of qualitative and quantitative phase analyses of the AlSi7Mg with $\mathrm{SiC}$ and graphite additions.

\begin{tabular}{|c|c|c|c|c|c|c|c|c|c|c|}
\hline \multirow{3}{*}{ Phase } & \multirow{3}{*}{$\begin{array}{c}\text { ICDD } \\
\text { database } \\
\text { number }\end{array}$} & \multirow{3}{*}{$\begin{array}{l}\text { Space } \\
\text { group }\end{array}$} & \multicolumn{8}{|c|}{ "Additions SiC + graphite [vol.\%] } \\
\hline & & & \multicolumn{2}{|c|}{$5+0$} & \multicolumn{2}{|c|}{$10+0$} & \multicolumn{2}{|c|}{$15+0$} & \multicolumn{2}{|c|}{$10+10$} \\
\hline & & & $\mathrm{L}$ & $\mathrm{S}$ & $\mathrm{L}$ & $\mathrm{L}$ & $\mathrm{S}$ & $\mathrm{S}$ & $\mathrm{L}$ & $\mathrm{S}$ \\
\hline $\mathrm{Al}$ & 01-089-4037 & $F m \overline{3} m$ & 96.1 & 94.5 & 62.6 & 63.1 & 78.4 & 96.7 & 63.1 & 78.4 \\
\hline SiC-6H & 04-007-1548 & $P 6{ }_{3} m c$ & 1.3 & 2.4 & 25.1 & 21.0 & 16.2 & - & 21.0 & 16.2 \\
\hline $\mathrm{SiC}-4 \mathrm{H}$ & $00-029-1127$ & $P 6_{3} m c$ & - & - & 10.0 & 11.9 & 3.0 & - & 11.9 & 3.0 \\
\hline $\mathrm{Si}$ & 01-089-2955 & $F d \overline{3} m$ & 0.8 & 0.5 & 1.9 & 2.6 & 1.7 & 2.2 & 2.6 & 1.7 \\
\hline $\mathrm{Mg}_{2} \mathrm{Si}$ & 98-064-2831 & $F m \overline{3} m$ & 1.9 & 2.6 & 0.5 & 1.4 & 0.6 & \begin{tabular}{|l|}
1.1 \\
\end{tabular} & $\begin{array}{ll}1.4 \\
\end{array}$ & 0.6 \\
\hline
\end{tabular}

Diffraction pattern analysis shows that there are no significant differences in the phase composition between long and short diagonal. However, at the edge of samples, we could observe some differences in amount of phases versus sample orientation which indicate presence of the inhomogeneity. Figure 2 shows the comparison of the XRD patterns of studied materials.

The XRD analyses show the presence of aluminum phase and different polymorphic forms of silicon carbide, mainly $\mathrm{SiC}-6 \mathrm{H}$ and $\mathrm{SiC}-4 \mathrm{H}$ polytypes. Additionally, there are detected traces of $\mathrm{Mg}_{2} \mathrm{Si}$ and $\mathrm{Si}$ phases. In the sample containing 15 vol.\% of $\mathrm{SiC}$, in the diffraction pattern there is observed a deficiency of the silicon carbide phases. It could be an effect of two phenomena: first,

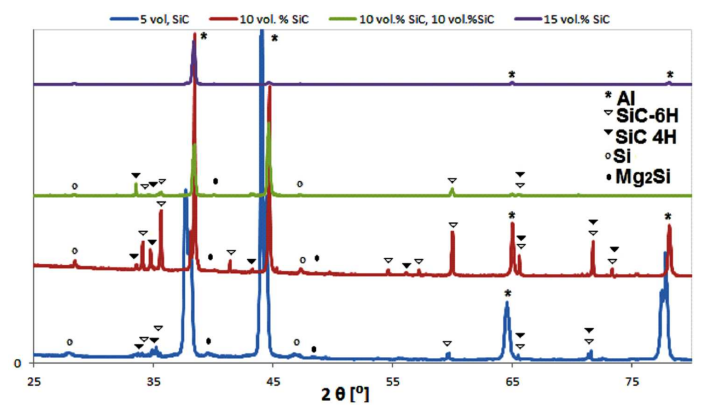

Fig. 2. XRD patterns obtained for the AlSi7Mg matrix with different amount of $\mathrm{SiC}$ additive.

inhomogeneity in the top of material layers, $\mathrm{SiC}$ particle create agglomerates in the deeper areas of materials; secondly, SiC grains are able to remove during the EDM process (wettability between ceramic reinforcement and matrix should be improved).

\section{Residual stress}

\subsection{The classical $\sin ^{2} \psi$ method}

Residual stresses can be defined as the effect of manufacture and processing in the absence of external forces. The most commonly used method for X-ray stress determination is the $\sin ^{2} \psi$ method. For the residual stress determination for aluminum matrix Eq. (1) $[7,8]$ is used. The values of the Young modulus $E$ and the Poisson coefficient $\nu$ are [9]: $E=70.14 \mathrm{GPa}$ and $\nu=0.3499$, are used.

$$
\frac{d_{\psi}-d_{0}}{d_{0}}=\frac{1+\nu}{E} \sigma \sin ^{2} \psi
$$

$\psi$ - tilt angle, $d_{0}$ - the stress-free lattice spacing, $d_{\psi}$ the lattice spacing measured in the stress sample with the orienation $\psi, E$ - the Young modulus, and $\nu-$ the Poisson ratio. In the present studies, the residual stress calculations were performed by considering the $\mathrm{Al}$ (420) line. In Table IV, the results of residual stresses for material containing different amount of silicon carbide addition are shown. For all of materials (apart from 10 vol.\% addition of $\mathrm{SiC}$ ) the results of residual stress are shown compressive character and they are comparable for all directions $\left(\varphi=0^{\circ}, \varphi=45^{\circ}, \varphi=90^{\circ}\right.$ and $\left.\varphi=135^{\circ}\right)$.

\section{TABLE IV}

The results of the residual stress $\sigma$ [MPa] obtained using classical $\sin ^{2} \psi$ method for AlSi7Mg with different amount of additions (as in Table III). $\Delta \sigma \approx 10-20 \%$.

\begin{tabular}{c|c|c|c|c}
\hline \hline$\varphi$ & $5+0$ & $10+0$ & $15+0$ & $10+10$ \\
\hline 0 & -199.7 & 94.9 & -56.7 & -33.6 \\
\hline 45 & -121.3 & -151.2 & -42.9 & -0.3 \\
\hline 90 & -128.7 & -143.2 & -52.2 & -64.6 \\
\hline 135 & -143.3 & -95.5 & -95.5 & 26.3
\end{tabular}




\subsection{GIXD method}

Residual stresses measured by the classical method have shown a presence of high level of stresses distribution on the cutting surface. In the next step the residual stress were measured using grazing incident X-ray diffraction (GIXD) technique $\left(g-\sin ^{2} \psi\right.$ method) based on the multireflection method [10]. It could provide the structure characterization of the material layers depending on the depth. Depth of X-ray penetration and consequently layer thickness could be calculated using Eqs. (2) and (3).

$$
\begin{aligned}
& Z_{\mathrm{BB}}=\frac{-\ln \left(1-G_{X}\right)}{2 \mu} \sin \theta, \\
& Z_{\mathrm{GIXD}}=\frac{-\ln \left(1-G_{X}\right)}{\mu\left(\frac{1}{\sin \alpha}+\frac{1}{\sin (2 \theta-\alpha)}\right)},
\end{aligned}
$$

where $Z_{\mathrm{BB}}$ - effective X-ray penetration depth in the Bragg-Brentano geometry, $Z_{\mathrm{GIXD}}$ - effective X-ray penetration depth in GIXD geometry, $\mu$ - linear absorption coefficient, $\theta$ - diffraction angle, $G_{X}$ - informative fraction of diffracted X-ray beam $\left(G_{X}=0.95\right), \alpha$ - angle of incident beam.

The residual stress values are determined for each of layers in the studied material. There is no significant difference in the phase composition after GIXD. The obtained results of residual stress analyses for aluminum phase are presented in Table V.

\section{TABLE V}

The results of the residual stress $\sigma[\mathrm{MPa}]$ obtained using $g-\sin ^{2} \psi$ method for AlSi7Mg with different amount of

\begin{tabular}{|c|c|c|c|c|c|c|}
\hline \multicolumn{2}{|c|}{ Geometry } & \multirow{2}{*}{$Z[\mu \mathrm{m}]$} & \multicolumn{4}{|c|}{$\sigma$} \\
\hline XRD & $\alpha\left[^{\circ}\right]$ & & $5+0$ & $10+0$ & $15+0$ & $10+10$ \\
\hline \multirow{3}{*}{ 齐 } & 1 & $\approx 3$ & -80.0 & 36.6 & 206.8 & $\begin{array}{l}-199.1 \\
\end{array}$ \\
\hline & 3 & $\approx 10$ & -104.4 & -77.5 & 188.1 & -133.0 \\
\hline & 15 & $\approx 40$ & -153.9 & 36.6 & -88.9 & -164.2 \\
\hline \multicolumn{2}{|c|}{ B-B } & up to 110 & -35.0 & -69.9 & -64.9 & -187.0 \\
\hline
\end{tabular}
amount of additions (as in Table III). $\Delta \sigma \approx 10-20 \%$.

For material containing 5 vol. $\%$ of $\mathrm{SiC}$, the residual stress analyses have shown the same comprehensive character. In materials with $10 \mathrm{vol} . \%$ and 15 vol.15\% content of silicon carbide great gradients of stresses occur. Depending on the X-ray penetration depth the values and stress character are changing.

\section{Conclusion}

- The XRD analyses show presence of aluminum phase and polymorphic forms of $\mathrm{SiC}$ phases in all studied materials.
- As a result of inhomogeneity in the top of layers, there occurs formation of $\mathrm{SiC}$ agglomerate in the whole volume of materials. There is observed deficiency of $\mathrm{SiC}$ particles in materials containing 15 vol.\% SiC.

- The addition of the silicon carbide particles indicated the presence of compressive residual stress in the range of 50-150 $\mathrm{MPa}$.

\section{Acknowledgments}

This work was supported by the Applied Research Programme: "The selection of phase composition of the AlSi matrix composite for the possibility of shaping work surfaces of pistons", KOMPCAST, No. PBS1/B6/13/2013 and by the statutory activity D.S.14-4.1.3 in the Institute of Advanced Manufacturing Technology.

\section{References}

[1] R. Riedel, Handbook of Ceramic Hard Materials, Vol. 1, Wiley-VCH, Weinheim 2000.

[2] M. Kunieda, B. Lauwers, K.P. Rajurkar, B.M. Schumacher, CIRP Annals Manufact. Technol. 54, 64 (2005).

[3] G. Cusanelli, A. Hessler-Wyser, F. Bobard, R. Demellayer, R. Perez, R. Flükiger, J. Mater. Process. Technol. 149, 289 (2004).

[4] M. Gostimirovic, P. Kovac, J. Mech. Sci. Technol. 26, 173 (2012).

[5] M. Karolus, J. Cyboroń, P. Putyra, M. Dyzia, W. Ratuszek, Mechanik 2, 319 (2015).

[6] A.J. Dolata, M. Dyzia, IOP Conf. Series Mater. Sci. Eng. 35, 1 (2012).

[7] B. McCusker, R.B. VonDreele, E.D. Cox, D. Louer, P. Scardi, J. Appl. Crystallogr. 32, 36 (1999).

[8] S.J. Skrzypek, New Approach to Measuring Residual Macro-Stresses with the Application of the Grazing Angle X-Ray Diffraction Geometry, Uczelniane Wydawnictwa Naukowo-Dydaktyczne, Kraków 2002 (in Polish).

[9] H. Wawra, D. Kröner, Z. Metallkd. 69, 518 (1978).

[10] A. Baczmański, C. Braham, W. Seiler, Philos. Mag. 83, 3225 (2003). 